\title{
'Requirements for Coordination and the Application of an Automatic Collision Avoidance System'
}

\author{
John Vendrell
}

May I congratulate Chris Perkins and Tony Redfern for their excellent paper ${ }^{1}$ in the May issue of the Journal. For many years I have read in the Journal, and on occasions listened to, learned ladies and gentlemen discoursing on the subjects of safe navigation and collision avoidance. Also to what I believe are their misguided wanderings into 'ship domains' and assumptions that ships behave as atomic particles. Thus it was very refreshing to read the latest and practical contribution by Chris and Tony. Well done chaps!

In the matter of collision avoidance I have, with respect, contributed modestly to the debate in the pages of the Journal ${ }^{2}$. This contribution was made as a practical seaman with some 52 years' experience as a watchkeeping officer and ship's master. As such, I have always marvelled at the criticisms and seemingly easy solutions offered by the academic fraternity on both safe navigation and collision avoidance, and have been left wondering if the various contributors have ever been on the bridge of a ship in inclement weather, with or without radar, and with the dictates of market forces depleting crews and throwing more and more responsibility on the unfortunate officer of the watch.

Incidentally, in my retirement, I devote some time each spring, on behalf of insurance companies, to conducting 'condition surveys' for private yachts. I try hard to impress on the yachtsmen the basic requirements of practical navigation but, nevertheless, I find that many are allowed by their insurance policies to put to sea without charts or a means of taking bearings. Some of them even have a total disregard of compass error, - and this in an area where variation alone is of the order of $10^{\circ}$ west.

\section{REFEREN CES}

1 Perkins, C. and Redfern, A. (1996). Requirements for coordination and the application of an automatic collision avoidance system. This Journal, 49, 29.

2 Vendrell, J. (1976). Rate and ratio in radar collision avoidance. This Journal, 29, 90.

\section{KEY WORDS}

1. Collision avoidance. 2. Safety. 